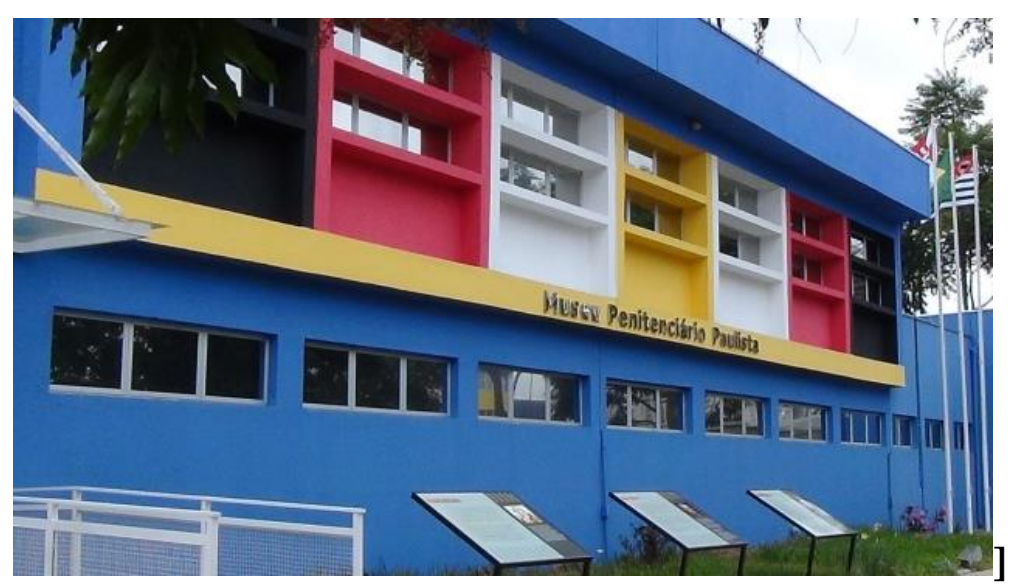

\title{
Versões controversas na leitura de arquivos: o Museu Penitenciário Paulista
}

Controversial versions in the archive reading: the Paulista penitentiary museum

\author{
Débora Massmann ${ }^{1}$ \\ https://orcid.org/0000-0002-3401-2291
}

\section{Resumo:}

Este trabalho analisa o processo de produção de sentidos em um espaço simbólico muito específico, a saber, o Museu Penitenciário Paulista (MPP). A partir do dispositivo teóricoanalítico da Análise de Discurso, compreendeu-se que o museu, como arquivo e como interdiscurso, se configura na relação com o espaço urbano, com as instituições e com as condições de produção (artefatos, visitantes, etc.). As análises apontam para as versões controversas que são postas em funcionamento pelo Museu Penitenciário Paulista na produção de um discurso autoritário em que a única versão aceita, aparentemente, é aquela do Estado.

Palavras-chave: Linguagem. Sociedade. Discurso. Museu. Carandiru

\section{Abstract:}

This paper analyses the meaning production process in a very specific symbolic place, as follows, the Paulista Penitentiary Museum (PPM). As held by the Discourse Analysis theoretic-analytical procedures, it was understood that the museum, as archive and as interdiscourse, is characterized in the relation with the urban space, with the institutions and with the production conditions (visitors, artefacts, and so on). The analysis shows many controversial versions that function by the Paulista Penitentiary Museum in the production of an authoritarian discourse in which the only acceptable version, apparently, is the one of the State.

Keywords: Language. Society. Discourse. Museum. Carandiru.

\footnotetext{
${ }^{1}$ Possui Doutorado em Letras pela Universidade de São Paulo (USP). É docente permanente do Programa de Pós-Graduação em Ciências da Linguagem (PPGCL) da Universidade do Vale do Sapucaí (UNIVAS). Email: deboraquel.hm@gmail.com e debora.massmann@univas.edu.br
} 


\title{
Considerações iniciais
}

\begin{abstract}
"não há "fato" ou "evento" histórico que não faça sentido, que não peça interpretação, que não reclame que lhe achemos causas e consequências.

É nisso que consiste para nós a história, nesse fazer sentido, mesmo que possamos divergir sobre esse sentido em cada caso"
\end{abstract}

(Paul Henry)

Do ponto de vista teórico das ciências da linguagem, sobretudo, a partir dos estudos em análise de discurso, compreende-se o espaço urbano antes de tudo como um espaço simbólico. Ele é discurso. Refletir sobre esse espaço urbano significa refletir sobre o sujeito, a história, a memória e o processo de produção de sentidos que daí deriva. Como ensina Orlandi (2004, p. 11) "o corpo dos sujeitos e o corpo da cidade formam um, estando o corpo do sujeito atado ao corpo da cidade, de tal modo que o destino de um não se separa do destino do outro". Fundamentado nas palavras da autora, este estudo se propõe a investigar versões controversas na leitura de arquivo e faz isso tomando como objeto de estudo uma instituição social inserida no espaço urbano, a saber, o museu. No âmbito dos estudos discursivos, muitos pesquisadores têm se dedicado a analisar este objeto simbólico (museu) na sua relação com a história, com a memória, com o sujeito e com os sentidos. Trata-se, como destaca Sobrinho (2011, p.20), de buscar compreender os efeitos de sentidos do museu, tomado aqui como discurso, "por uma análise de seu funcionamento discursivo". Para isso, é necessário produzir deslocamentos importantes no modo de dizer, de analisar e de compreender o funcionamento do museu enquanto instituição de memória, arquivo (Venturini, 2017). Dito de outra forma, tomar o museu como um objeto discursivo implica deslocá-lo

da perspectiva da informação, da documentação, das questões da memória histórica, da preservação e da conservação para a perspectiva da análise discursiva da historicidade do Museu, que considera como constitutiva dessa instituição as suas relações com outras instituições, com outros objetos simbólicos, com as suas condições de produção e com o interdiscurso, a memória do dizer (Sobrinho, 2011, p. 20)

Compreendido como espaço simbólico, o museu é espaço de linguagem e, consequentemente, de significação. Este modo de significar o museu se sustenta, sobretudo, nas palavras de Orlandi $(2014 \text {, p. } 2)^{2}$ para quem o museu é, em primeira

\footnotetext{
${ }^{2}$ Entremeios: revista de estudos do discurso. v.9, jul/2014
} 
instância, uma instituição de memória discursiva que produz efeitos no processo de individuação dos sujeitos que são "afetados pela forma como o Estado relaciona os sujeitos com sentidos sociais que se apresentam como parte de sua memória" (isto é, como parte da memória do indivíduo, do Estado, da Sociedade)" (Orlandi, 2014, p. 2). De acordo com a autora, há que se considerar, em segunda instância, o museu também "como parte do processo de produção de arquivos, ou seja, discursivamente, como discurso documental” (Orlandi, 2014, p. 3). Em outras palavras, Orlandi considera o museu como "prática de significação", dizer em curso, efeito de sentido entre interlocutores.

Quando visitamos um museu, somos levados a pensar, a refletir e, muitas vezes, a (nos) questionar sobre aquele conjunto de artefatos simbólicos que compõem aquela instituição. Entendemos aqui como artefatos simbólicos o próprio espaço (museu X ou Y) e todos aqueles materiais que compõem um museu: quadros, fotografias, áudios, vestimentas, maquetes, utensílios, mapas, etc.. Então, para mim, os museus são espaços de produção de sentidos porque, à medida que nos deparamos com os artefatos simbólicos presentes nos museus, somos interpelados por eles e, nesse processo, colocamos em funcionamento gestos de leitura. Consequentemente, somos levados a interpretar o museu e os sentidos produzidos nele, por ele e para ele. Não podemos esquecer que, como destacou Orlandi, "somos individuados pelo Estado através de instituições e discursos" (Orlandi, 2014, p. 2). Isso significa que os gestos de leitura e de interpretação que se produzem nesse espaço institucional, que é o museu, não se dão ao acaso. Ao contrário, esses gestos trazem consigo traços da memória discursiva do próprio indivíduo, do Estado e da Sociedade.

Dizer que os museus constituem práticas de significação (Orlandi, 2014), ou ainda, que são espaços simbólicos de produção de sentidos significa, pois questioná-los e analisá-los numa perspectiva discursiva: como espaço significante, como arquivo e como interdiscurso, isto é, memória discursiva. Nessa perspectiva, os museus se configuram, significam e são significados (1) na relação com o espaço urbano em que estão localizados, (2) na relação com outras instituições da sociedade; (3) na relação com outros objetos simbólicos; (4) com as condições de produção; e, sobretudo, (5) na relação com o sujeito visitante. Trata-se, pois, de tomar os museus, em sua historicidade, como espaços institucionais, espaços simbólicos e políticos afetados pelas relações de poder e pela conjuntura sócio-histórica e ideológica.

Nesse sentido, trabalhar aqui com versões controversas na leitura de arquivos implica, pois considerar, como nos ensinou Orlandi, o museu nesta sua dupla designação: 
como instituição e como "como parte do processo de produção de arquivos, ou seja, discursivamente, como discurso documental" (Orlandi, 2014, p.2). Nessa perspectiva, a noção de "arquivo" é fundamental para esta reflexão e, é importante destacar, se distingue da noção de acervo. Este, o acervo, conceito comum para historiadores, museólogos e curadores, pode ser descrito como um espaço de registro da memória histórica organizado por uma instituição. Em outras palavras, o acervo representa um conjunto de materiais (documentos, objetos e outros artefatos simbólicos) que foram mapeados, classificados, preservados e armazenados por determinada instituição sobre um assunto ou época específicos. Trata-se, pois, de um conjunto de materiais (ou coleções) que foi organizado por alguém, sobre alguma coisa, com objetivos específicos (de caráter bibliográfico, artístico, fotográfico, científico, histórico, documental, etc.). A noção de acervo já traz consigo um filtro, uma interpretação, um olhar direcionado. Ele é reflexo passivo de uma realidade institucional. O arquivo, por sua vez, dentro de sua forma material e da heterogeneidade que lhe é constitutiva, é "ordenado por sua abrangência social" (Guilhaumou e Maldidier (2014, p.170). Então, como nos ensinam Guilhaumou e Maldidier (2014, p.170), o arquivo "não é um simples documento no qual se encontram referências; ele permite uma leitura que traz à tona dispositivos e configurações significantes" (Guilhaumou e Maldidier (2014, p.170). Para Pêcheux (2014, p. 59), o arquivo é um campo discursivo de "documentos pertinentes e disponíveis sobre uma questão".

Essas definições de arquivo trazem consigo questões absolutamente relevantes para nós analistas de discurso, a saber, a questão do corpus e a questão da leitura. $\mathrm{O}$ corpus, descrito como um conjunto de documentos, de formulações, já é o resultado (o produto) de um processo de interpretação do discurso na sua relação com as condições de produção, ou melhor, na "relação com a materialidade da língua, com a história, com o real" (Guilhaumou e Maldidier, 2014, p. 177). Em relação à questão da leitura do arquivo, Pêcheux (2014, p. 59) destaca que pode haver "maneiras diferentes, ou mesmo contraditórias, de ler o arquivo". Isso porque a leitura do arquivo parece produzir um efeito de deslocamento neste entremeio do sentido estabilizado e do sujeito a equívoco. Trata-se, pois do trabalho de interpretação. Ou ainda, como destaca Orlandi (2014, p. 2), “trabalho da memória em perpétuo confronto consigo mesma. E é neste confronto da memória com a memória - o [confronto] da cultura do literário (sujeito a interpretação) e o [confronto] do científico (sentidos estabilizados) - que se aloja o vai e vem da interpretação, dos gestos de leitura e da força do imaginário". Tem-se assim que as 
versões controversas na leitura de arquivos são, pois, produzidas pela relação de interpretação que resulta da triangulação arquivo, sujeito e sentido(s). Essa leitura controversa do arquivo é o indício do funcionamento do político na linguagem. E o político, na análise de discurso, é compreendido, como divisão: “divisão da sociedade, divisão dos sujeitos, divisão do sentido, em que faz funcionar, na sociedade capitalista, relações de poder simbolizadas" (Orlandi, 2013, p. 28). Essa divisão, de acordo com Orlandi (1998), tem uma direção que é afetada pelas relações de força oriundas das formas da sociedade na história. Dessa perspectiva, o político pode ser entendido como conflito, a partir das diferentes posições sujeito que são assumidas em discurso. Dito isso, é importante observarmos como essas versões controversas são produzidas na leitura do arquivo "Museu Penitenciário Paulista".

\section{Sobre o museu penitenciário paulista}

Dentre os diversos museus da cidade de São Paulo, selecionou-se como objeto de estudo Museu Penitenciário Paulista que, no mês de julho de 2017, completou 3 anos de funcionamento. Considerando este museu em sua forma material, direcionamos nosso olhar, nesta reflexão, de modo específico, ao painel em que se apresenta a linha do tempo historicizando a criação e a consolidação do sistema penitenciário de São Paulo. Essa linha tempo funciona e produz sentidos na relação com a história, com a memória e com o sujeito. Como destaca Sobrinho (2011, p. 20), os museus e suas exposições "funcionam na história. É aí que (...) significam. Está aí a sua ordem, a sua materialidade”.

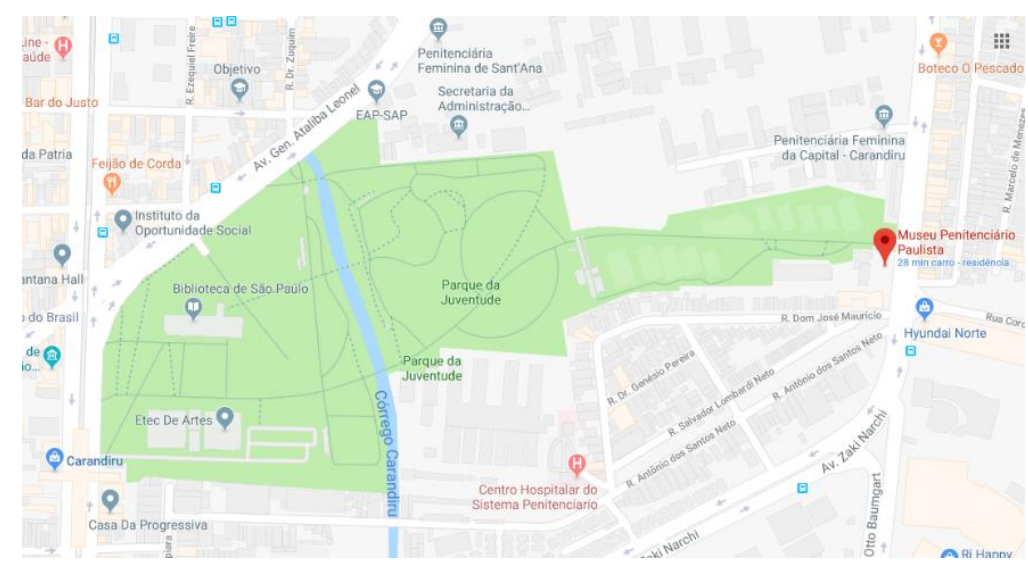

Imagem 1: Localização Parque da Juventude e Museu Penitenciário Paulista.

Fonte: GoogleMaps.

URL:https://www.google.com/maps/place/Museu+Penitenci\%C3\%A1 rio+Paulista/@-23.507452,46.6201255,17z/data $=! 4 \mathrm{~m} 5 ! 3 \mathrm{~m} 4$ ! $1 \mathrm{~s} 0 \times 0: 0 \times 54680 \mathrm{c} 2 \mathrm{~d} 8963 \mathrm{e} 8 \mathrm{c} 8$ ! $8 \mathrm{~m} 2 ! 3$ d-23.506949!4d-46.615601?hl=pt-BR. Acesso em 12 mar. 2018. 
Localizado na Avenida Záki Nárchi, 1.207, zona norte de São Paulo, em uma pequena edificação que constitui o complexo cultural do chamado Parque da Juventude, o Museu Penitenciário Paulista, como discurso, textualiza o funcionamento do político na linguagem pelo modo como se inscreve no espaço urbano. Este mesmo endereço abrigou, por muitas décadas, o Complexo Penitenciário do Carandiru que era composto pela Casa de Detenção "Prof. Flamínio Fávero", pela Penitenciária do Estado de São Paulo, pela Penitenciária Feminina da Capital e pelo Centro de Observação Criminológica (COC). Distribuído em um total de 9 pavilhões, o complexo do Carandiru foi palco de um dos acontecimentos mais trágicos do universo prisional brasileiro tanto por questões jurídicas e de segurança pública, quanto por questões políticas e sociais: em 1992, uma ação da Polícia Militar de São Paulo, enviada para controlar uma rebelião no pavilhão 9, da Casa de Detenção, resultou na morte de cento e onze (111) detentos. O impacto dessa tragédia comoveu o país e serviu de inspiração para diferentes produções bibliográficas e cinematográficas. O episódio deixou suas marcas na história, na cidade, na sociedade e nos sujeitos.

Dos nove (9) pavilhões que compunham o Complexo Penitenciário do Carandiru, hoje, temos a seguinte configuração: cinco foram implodidos a partir de 2002, dois são ainda ocupados pela penitenciária feminina (cujo muro faz divisa com o Parque da Juventude) e dois foram reformados para abrigar a biblioteca do Estado de São Paulo e a Escola Técnica Carandiru. No entorno dessas instalações, encontram-se espaços de lazer colocados à disposição da comunidade. Esses mesmos espaços, num passado recente, eram ocupados pelos detentos e, hoje, re-significados, compõem o Parque da Juventude. Ou seja, o museu, ao estar situado neste espaço urbano, produz e faz circular, de um lado, sentidos institucionalizados pela memória e/ou pela história daquele endereço: no passado, as rebeliões dos detentos do Carandiru e, no presente, há ainda a penitenciária feminina que continua situada por ali, no entorno. Observa-se que há algo dessa memória discursiva sobre o espaço urbano que materialmente se mantém, se atualiza; de outro lado, a atual nomeação deste espaço urbano como "parque da juventude" produz efeitos de ruptura no processo de significação: isto é, o gesto de nomeação "parque da juventude"3 produz aí uma tentativa de ressignificação, entretanto, para nós, analistas de discurso, tal gesto põe em funcionamento o embate do simbólico com o político e produz efeitos de apagamento não só dos fatos que estão ali a reclamar sentidos (Henry, 2014), mas

\footnotetext{
${ }^{3}$ A relação que se estabelece entre nomeação, memória e espaço urbano está sendo desenvolvida em um artigo específico que se encontra no prelo.
} 
sobretudo, da memória daquele espaço urbano. A história do espaço urbano passa a ser então gerenciada, controlada, já que "pelo funcionamento da memória realizam-se (...) coerções sociais" (Venturini, 2009, p. 34) que se sustentam em relações de poder, no discurso que pode legitimar essa nomeação, a saber, aquele do Estado.

É, pois, no Complexo Penitenciário do Carandiru, no mesmo endereço, no mesmo espaço urbano em que aconteceu este episódio marcante para o sistema penitenciário brasileiro, que o Museu Penitenciário Paulista está situado. Essa localização já produz sentidos para este museu na sua relação com a história e com a memória da cidade de São Paulo. Segundo o site do MPP 4 , a localização é "estratégica por se tratar de lugar histórico para o Sistema Penitenciário Paulista”. Já num gesto inicial de análise sobre as versões controversas na leitura de arquivo, questiona-se: estratégica para quem? E por quê? Essa localização é estratégica para que se esqueça o que aconteceu ali, num gesto absoluto de apagamento e/ou de silenciamento ou para que aquele episódio seja lembrado pela sociedade a fim de que confrontos como aquele não se repitam? Fato é que este endereço já faz significar o museu na sua relação com a cidade de São Paulo e produz sentidos no percurso dos sujeitos no espaço urbano: o que foi o Carandiru? Que memória de sentidos este espaço urbano põe em funcionamento? Qual é a relação do museu com o este espaço em que ele está instalado? O que simbolicamente e discursivamente tem da cidade no museu?

Inaugurado em julho de 2014, a proposta do Museu Penitenciário Paulista é exibir “o acervo relacionado à ressocialização e à cultura prisional” e "propiciar a reflexão sobre

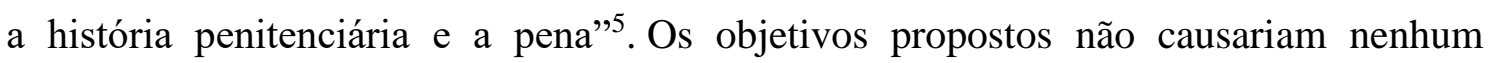
estranhamento se o Museu Penitenciário Paulista estivesse, por exemplo, filiado à Secretaria de Cultura do Estado de São Paulo. No entanto, ele faz parte da estrutura mantida pela Secretaria de Administração Penitenciária do Estado. Isso, para nós, analistas de discurso, já se coloca como um ponto muito relevante na questão do arquivo. Trata-se, como se destacou anteriormente, da questão do corpus e de suas condições de produção, ou seja, qual é a versão dos fatos que será apresentada neste museu: aquela do Estado ou aquela dos detentos? Certamente, as versões são inúmeras. Compreendido como objeto discursivo, o Museu Penitenciário Paulista pode produzir uma grande diversidade de gestos de leitura e de interpretação. Isso pode ser observado à medida que iniciamos a visita física no MPP. Destacamos aqui alguns espaços de exposição do MPP

\footnotetext{
${ }^{4}$ In http://museupenitenciario.blogspot.com.br/. Acesso em 13 mai. 2017.

${ }^{5} \mathrm{In}:$ http://museupenitenciario.blogspot.com.br/p/quem-somos.html. Acesso em 13 mai. 2017.
} 
que apontam justamente para as versões controversas na leitura deste arquivo. Trata-se de espaços que, neste momento, para nós, estavam, neste gesto de leitura, a reclamar sentidos.

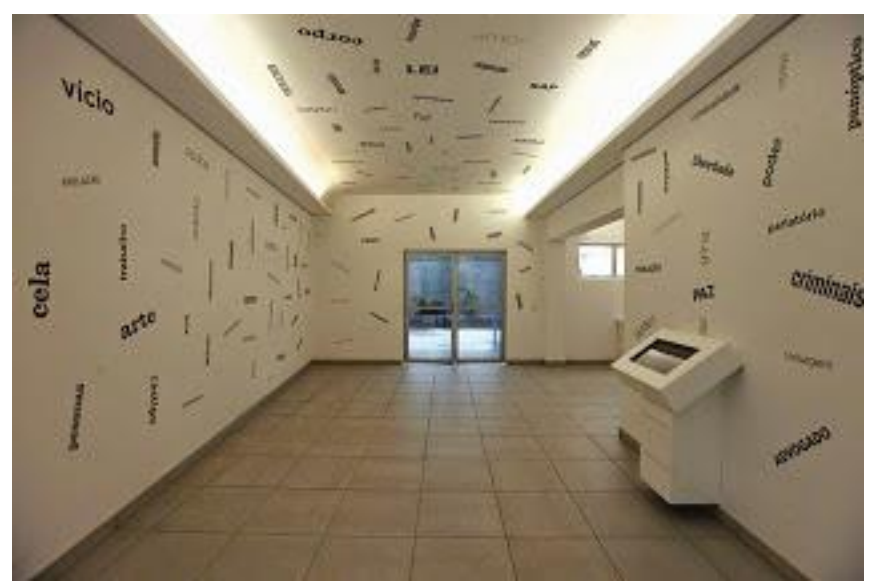

Imagem 2: Foyer Museu Penitenciário Paulista

Fonte: Museu Penitenciário Paulista

In:http://museupenitenciario.blogspot.com.br/2014/11/areas

-do-museu-penitenciario-paulista.html Acesso em 12

mar.2018

A exposição do MPP está distribuída em quinze salas/espaços. Logo no Foyer de entrada, espaço destinado à recepção e identificação, uma "Chuva de palavras" recebe aos visitantes com termos do universo penitenciário, mais especificamente, terminologia jurídica, propondo-se assim uma ambientação. De acordo com o site do MPP, a apresentação de conceitos do Direito Penitenciário, desde a área externa do museu, é uma preparação para a visita cujo itinerário (idealizado pela administração do Museu) pretende mostrar uma historizciação sobre o conceito de pena. Nessa chuva de palavras, já na recepção, são apresentados mais de 80 vocábulos, entretanto, aproximadamente $10 \%$ deles remetem diretamente às gírias e ao modo de expressão dos detentos. Ou seja, a maioria dos termos selecionados para "ambientar o visitante" refere-se, de fato, conforme indicado no site do museu, a expressões jurídicas relativas ao Direito Penal. Isso aponta para uma direção de sentidos, uma direção de leitura e de interpretação para a visita. Eis o funcionamento das relações de força que se sustentam em um discurso autoritário que tende sempre para o mesmo ou, nas palavras de Orlandi, que

tende para a paráfrase (o mesmo) e em que se procura conter a reversibilidade (há um agente único: a reversibilidade tende a zero), em que a polissemia é contida (procura-se impor um só sentido) e em que o objeto de discurso (seu referente) fica dominado pelo próprio dizer (o objeto praticamente desaparece) (Orlandi, 2008, p. 24-25). 
Após essa imersão na terminologia do direito penal, no interior do museu, na sala de número 4, somos convidados a percorrer a exposição que tem como tema o serviço de biotipologia. Nesse espaço, os visitantes são levados a conhecer uma "memória" institucionalizada sobre a antropologia criminal que influenciou a legislação penal e o sistema penitenciário brasileiro. Idealizada pelo médico italiano Cesare Lombroso, o método da biotipologia criminal ${ }^{6}$ era empregado para identificar traços da criminalidade através das características físicas, fisiológicas e psicológicas dos detentos. Segundo a técnica de Lombroso, haveria um "biótipo do criminoso". Com base em suas pesquisas, o médico italiano propôs a tese de que haveria indivíduos que pertenceriam a uma categoria de "delinquente nato"7. Essa teoria foi formulada com base em resultados de mais de quatrocentas autópsias de delinquentes e seis mil análises de delinquentes vivos. Dentre as características corporais dos indivíduos delinquentes, estariam: "protuberância occipital, órbitas grandes, testa fugidia, arcos superciliares excessivos, zígomas salientes, prognatismo inferior, nariz torcido, lábios grossos, arcada dentária defeituosa, braços excessivamente longos, mãos grandes, anomalias dos órgão sexuais, orelhas grandes e separadas, polidactia. As características anímicas, segundo o autor, são: insensibilidade à dor, tendência a tatuagem, cinismo, vaidade, crueldade, falta de senso moral, preguiça excessiva, caráter impulsivo" 8 .

Com base no método, idealizado por Lombroso, em 1939, foi proposto o Serviço de Biotipologia Criminal da Penitenciária do Estado de São Paulo que passou a funcionar efetivamente no ano seguinte, no governo de Adhemar de Barros, período em que o Brasil vivia a ditadura Vargas (foi Getúlio Vargas, inclusive, que, 1920, autorizou a construção da casa penitenciária). A função do Serviço de Biotipologia Criminal era fazer a medição dos detentos brasileiros e categorizar seus traços, conforme as especificações de criminalidade propostas por Lombroso: as características físicas comuns aos sujeitos serviriam para classificar os crimes em X ou Y e contribuiriam para determinar a penalização. Segundo essa perspectiva, haveria pois um pré-construído físico-biológico da delinquência. As teses de Lombroso foram rechaçadas posteriormente em função de

\footnotetext{
${ }^{6}$ Termo cunhado, em 1939, por Nicola Pende, com a publicação do livro "Trattato Di Tipologia Umana". ${ }^{7}$ MOLINA, Antonio García-Pablos de; GOMES, Luiz Flávio. Criminologia, 4a edição, São Paulo, RT, 2002, p. 191.

${ }^{8}$ ALBERGARIA, Jason. Noções de Criminologia. Belo Horizonte, Mandamentos, 1999, p. 131.
} 
novas correntes do direito penal. Entretanto, no MPP, não há nenhuma referência aos questionamentos e às contestações em relação ao método de Lombroso.

Observa-se assim, a partir deste olhar sobre o Museu Penitenciário Paulista, que há um percurso de sentidos institucionalizado e imposto ao visitante. Aparentemente, há apenas uma memória sobre o sistema penitenciário paulista: aquela institucionalizada no e pelo museu. A mesma memória que está, por exemplo, exposta no site do MPP na seção intitulada "Memória Oral". Aqui, ao clicar no ícone "Áudio Acervo" ou "Memória Oral", o visitante é conduzido a outra página em que se pode acessar quatro áudios distintos, a saber,

- $1^{\circ}$ Ligeirinho, Agente Penitenciário;

- $2^{\circ}$ Senhor Luiz Camargo Wolfmann (Luizão), coordenador do Sistema Penitenciário;

- $3^{\circ}$ Senhor Maurício Guarnieri, Diretor Técnico III;

- $4^{\circ}$ Senhor Lourival Gomes, Secretário da Administração Penitenciária;

Observem que, na lista de sujeitos que têm o direito à palavra, aqueles cuja voz e história é registrada, não há nenhum depoimento de detento. A voz ouvida, registrada e armazenada neste arquivo online da instituição MPP é aquela dos agentes, administradores, coordenadores e diretores que, em algum momento, prestaram seus serviços ao Sistema Penitenciário Paulista. Novamente, observamos a presença de um discurso autoritário, de um sentido único para a história penitenciária de São Paulo.

Outro espaço do museu cuja reflexão se faz necessária é aquele em que se apresenta a linha do tempo do Complexo do Carandiru. Trata-se de um painel em que são representados os principais momentos que marcaram a história dessa instituição, desde o lançamento de sua pedra fundamental, em 1911, até a implosão dos pavilhões e a inauguração do Parque da Juventude em 2002, 2003 respectivamente. Observemos as imagens 3 e 4 aqui abaixo: 

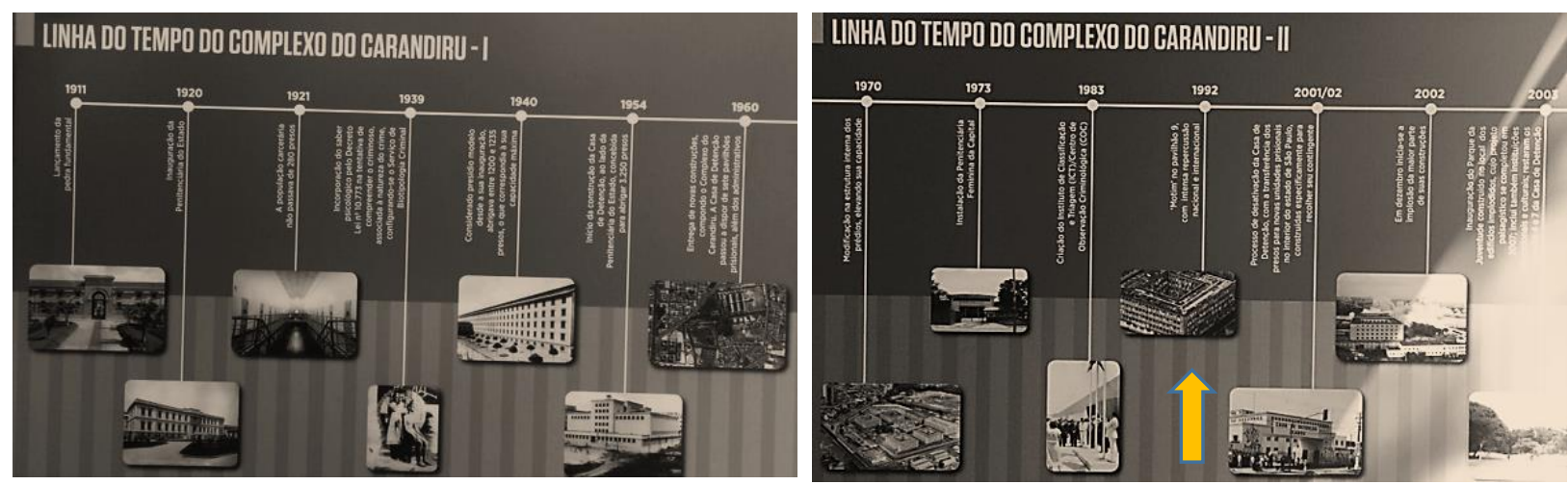

Imagem 3 e 4: Linha do tempo do Complexo Penitenciário do Carandiru I Acervo pessoal Fotógrafa: Patrícia Brasil

Neste eixo temporal, o ano de 1992 chama a atenção pelo modo como é descrito, conforme pode ser verificado na Imagem 4. Logo abaixo da data, tem-se a seguinte especificação:

"Motim" no pavilhão 9, com intensa repercussão nacional e internacional".9.

Notemos que, na versão da história que é contada pelo museu, a versão institucionalizada, o episódio de 1992 é descrito como "Motim". Destacamos que a palavra em questão aparece grafada entre aspas “ ”. Temos aí duas importantes entradas de análises: 1) o emprego da palavra "motim" para designar o episódio de 1992; e 2) o funcionamento das aspas que, neste caso, analisado discursivamente, nos leva a compreender aí um efeito para além de um simples sinal de pontuação. De fato, compreendidas como vestígios de um processo de produção de sentidos muito particular, as aspas permitem compreender um discurso-outro (Authier-Revuz, 2004), como veremos mais adiante.

\section{Sentidos: entre o Motim e o Massacre}

A fim de compreender os efeitos de sentidos do uso da palavra "motim" (empregada, na linha do tempo do MPP, para dar a conhecer aos seus visitantes, o que aconteceu em 1992), trazemos o verbete "motim", conforme descrito pelo Michaelis Dicionário Brasileiro da Língua Portuguesa ${ }^{10}$ :

\footnotetext{
${ }^{9}$ Grifo nosso.

${ }^{10} \mathrm{In}<$ http://michaelis.uol.com.br/moderno-portugues/busca/portugues-brasileiro/motim/>. Acesso em 13 mar. 2018.
} 


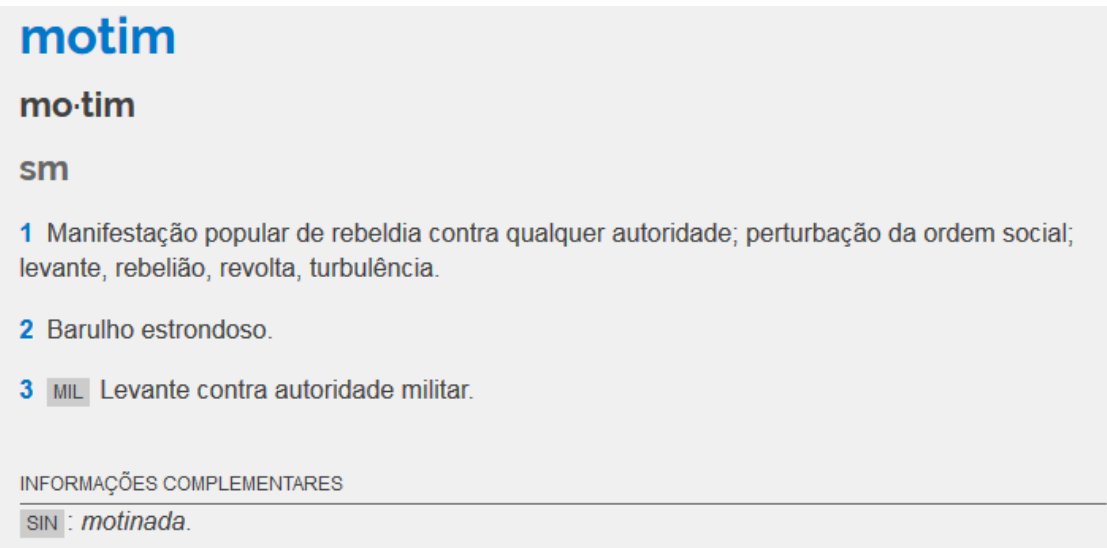

Imagem 5: Captura de tela da palavra "Motim"

Fonte: Dicionário Brasileiro de Língua Portuguesa

In:<http://michaelis.uol.com.br/moderno-portugues/busca/portugues-

brasileiro/motim/>. Acesso em 13 mar. 2018

Considerando sentidos estabilizados e cristalizados em e por este verbete (imagem 5) e conforme o discurso institucional do MPP, o episódio de 1992 pode ser compreendido como uma manifestação de detentos contra a autoridade penitenciária. No discurso documental exposto nesta linha do tempo, não há referência alguma sobre a invasão da polícia militar no pavilhão 9; não há referência alguma sobre os 111 detentos mortos; e não há também referência alguma sobre o desfecho do que se chamou, no discurso autoritário da instituição MPP, de "motim". Dentre os efeitos de sentido produzidos pelo emprego de "Motim", chamamos a atenção para o apagamento de "fatos históricos que aí estão a reclamar sentidos" (Henri, 2014, p.55. Nas condições de produção do Museu Penitenciário Paulista, a palavra "motim" põe em funcionamento relações de força e relações de poder no discurso, isto é, seu uso inscreve esse dizer na posição sujeito da autoridade, ou seja, do Estado.

Observamos assim que quem está sendo representado neste Museu é o Estado, o discurso dominante, o discurso de poder que vem institucionalizar, preservar uma, apenas uma, versão da memória sobre o Carandiru, 1992. À medida que se institucionaliza e se registra apenas uma versão, as outras são apagadas. Essa memória registrada, representada e institucionalizada no e pelo Museu Penitenciário Paulista promove um efeito de "apropriação do dizer" (Orlandi, 2002), isto é, faz parecer que o dizer sobre o acontecimento de 1992 é propriedade exclusiva do Estado e da Secretaria de Administração Penitenciária, entidades que são as mantenedoras do MPP. A única versão a ser posta em circulação, a partir deste ponto de vista do discurso institucionalizado (e autoritário), seria assim aquela do "motim". Como ensina Orlandi (2002, p. 32), "o dizer 
não é propriedade particular", entretanto, apropriar-se do dizer, tentar controlar o processo de produção de sentidos parece ser uma característica comum aos discursos do tipo autoritário que se emprenham em produzir uma memória institucionaliza, sobretudo, pelo Estado. Para avançarmos nessa reflexão, em um gesto de análise, substituímos a palavra "motim" pela palavra "massacre":

\section{“Motim” no pavilhão 9, com intensa repercussão nacional e internacional

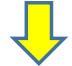 \\ "Massacre" no pavilhão 9, com intensa repercussão nacional e internacional}

Notemos aqui que, ao inserirmos a palavra "massacre" no pavilhão 9", outros sentidos são postos em funcionamento e permitem visualizar outras posições sujeito, outras versões para o arquivo. Versões que desestabilizam este discurso institucional do MPP. De fato, a substituição proposta traz consigo sentidos que vêm pela história sem pedir licença e vão se entrenhando na sua relação com a memória e com o arquivo pelas filiações de sentido que foram sendo constituídas em outros dizeres sobre o Carandiru. Outras versões e outras vozes passam ser audíveis. É, pois, nesta historicidade, neste ir e vir dos discursos e da língua que a leitura do arquivo vai se mostrando controversa. Dito de outra forma, a contradição, o dissenso, a divisão de sentidos na leitura de arquivo resulta do "jogo da língua que vai se historicizando aqui e ali, indiferentemente, mas marcada pela ideologia e pelas posições relativas ao poder" (Orlandi, 2002, p. 32).

\section{Sentidos, entre aspas}

Ainda em relação ao recorte em análise, a saber, "“"Motim” no pavilhão 9, com intensa repercussão nacional e internacional”, chama-nos a atenção, na linha do tempo do MPP, o fato de a palavra motim ser apresentada entre aspas. A utilização de aspas pode, para muitos, ser apenas o indício de um sinal gráfico de pontuação comum a diferentes línguas. Entretanto, para nós, analistas de discursos, qualquer marca de pontuação apresenta-se como uma marca importante do processo discursivo. Com efeito, a pontuação instala no fio do dizer as marcas da significação e das divisões da organização textual. Discursivamente, considerando que a língua funciona no equívoco, o maquinário da pontuação pode registrar na materialidade linguística a fronteira tênue entre aquilo que é dito e aquilo a ser interpretado. Compreende-se assim a pontuação como gesto de 
interpretação que aponta para a dispersão dos sentidos, para a incompletude. De acordo com Orlandi (2001, p. 113), a pontuação revela-se

um mecanismo de ajuste na relação discurso/texto, onde se manifesta o processo de subjetivação. Tomando a pontuação como vestígio da textualização, pelo jogo da interpretação, nós observamos como o sujeito se articula a um discurso, como ele se inscreve em uma formação discursiva, comprometendo-se com uma certa filiação de sentidos, ao fazer certos gestos de interpretação, produzindo dessa maneira um texto específico, em seus limites aparentes (ou seja, imaginários).

Nesse sentido, analisar o emprego das aspas na palavra "motim" implica observar os pontos de deriva, os índices de dispersão ou, como descreve Pêcheux (2008, p. 34), "detectar os momentos de interpretação enquanto atos que surgem como tomadas de posição reconhecidas enquanto tais, isto é, como efeitos de identificação assumidos e não negados". De fato, frente ao painel "Linha do tempo" do MPP, questionamo-nos: qual é o papel das aspas?

Para compreender o funcionamento das aspas, recorrermos a Authier-Revuz $(1998,2004)$, para quem o emprego de aspas precisa ser analisado com rigor uma vez que elas se constituem em "uma marca que deve ser interpretada" como referência a um outro discurso" (Authier-Revuz, 1998, p. 143). Para a autora, a aspas permitem ao locutor marcar, na materialidade linguística, um distanciamento nas palavras que produz. Dito de outra forma, as aspas constituem

a marca de uma operação metalinguística local de distanciamento: uma palavra, durante o discurso, é designada na intenção do receptor como o objeto, o lugar de uma suspensão de responsabilidade - daquela que normalmente funciona para as outras palavras. Essa suspensão de responsabilidade determina uma espécie de vazio a preencher, através de uma interpretação, um "apelo de glosa", se assim se pode dizer, glosa que, às vezes, se explicita, permanecendo mais frequentemente implícita (Authier-Revuz, 1998, p. 143).

Retornando ao nosso estudo, observamos que as aspas que contornam a palavra "motim" não parecem ter sido empregadas aí para marcar uma expressão familiar ou para distinguir essa palavra de outra, nem mesmo para indicar ênfase (só para elencar algumas das funções identificadas por Authier-Revuz (2004). Considerando as condições de produção do discurso do MPP, o uso de aspas na palavra "motim" parece marcar um distanciamento, apontar para um lugar/espaço de ruptura entre o discurso institucionalizado pelo MPP (e pelo Estado) e um discurso outro. O uso das aspas permite

\footnotetext{
${ }^{11}$ Grifo da autora.
} 
entrever um ponto de deriva, de possível ruptura deste discurso autoritário que temos verificado em nossas análises. Conforme o estudo de Authier-Revuz (2004, p. 225), as aspas manifestam imperfeições, falhas, deslocamentos. Apontam para algo que está na beirada, um vazio que se sustenta numa espécie de entre-dois: "se as aspas são a marca de uma imperfeição, trata-se de uma imperfeição constitutiva; se a palavra aspeada está 'na margem' de um discurso, não é no sentido de que seria desprezível, mas no sentido de que uma margem delimita e constitui" (Authier-Revuz ${ }^{12}, 2004$, p. 229). Assim, à medida que a palavra "motim" é marcada por essas aspas, ela é colocada na fronteira entre o dito, o não-dito e o a-se-dizer (ou a-se-interpretar) - que está, neste caso, funcionando como possibilidade de significação constitutiva deste discurso do MPP. As aspas marcam a iminência de outra versão, outros sentidos. Elas apontam para gestos de interpretação latentes que têm no equívoco, na borda, o ponto de encontro com outro(s) discurso(s) ou discurso(s) outro(s):

\begin{abstract}
aspas se fazem "na borda" de um discurso, ou seja, marcam o encontro com um discurso-outro. São uma balizagem dessa zona de demarcação mediante a qual, através de um trabalho sobre suas bordas, um discurso se constitui em relação a um exterior. Essa borda é, a um tempo só, reveladora e indispensável: acompanhar o mapeamento das palavras aspeadas de um discurso é acompanhar a zona fronteiriça reveladora daquilo em relação ao que lhe é essencial se distanciar: "Diz-me o que tu aspeias..."; ao mesmo tempo, é pelo fato de colocar algumas palavras como não apropriadas que um discurso constitui, em si mesmo, o complementar dessas palavras: palavras essas plenamente apropriadas, às quais o locutor supostamente adere sem distância; é o trabalho constitutivo das aspas (Authier-Revuz, 2004 p. 229).
\end{abstract}

Como se pôde observar, a análise sobre o emprego das aspas na palavra "motim" dá a conhecer mais alguns indícios, vestígios e marcas que, na discursividade do Museu Penitenciário Paulista, apontam mais uma vez para as versões controversas na leitura deste arquivo. As aspas são, pois, o rastro material de uma fronteira entre o discurso e a memória institucionalizados pelo Museu e as outras versões que circulam na sociedade sobre a história/memória penitenciária paulista. Essas aspas chancelam o elo discursivo entre o dito, o não-dito e o a-se-dizer (ou a-se-interpretar), ou melhor, entre o discurso do museu e(m) sua relação com a exterioridade.

\footnotetext{
${ }^{12}$ Grifos da autora.
} 


\section{Em vias de conclusão...}

A proposta trazida para reflexão neste estudo foi aquela de pensar o museu não só como instituição, mas também como prática de significação, isto é, como parte do processo de produção de arquivos (discurso documental). Orientados por essa perspectiva teórica, compreendemos que a construção de um Museu Penitenciário Paulista num espaço marcado por relações de força, violência, dor e morte poderia servir para a ressignificação da memória e história da sociedade, dos sujeitos, do Estado e do próprio espaço urbano. Desse modo, espaço urbano e Museu constituiriam lugares de memória (Nora, 1993) e representariam pontos de atualização e ressignificação do discurso de e sobre o Carandiru.

Entretanto, o projeto e o discurso documental que circulam no MPP, como todo discurso do tipo autoritário, buscam controlar a possibilidade de novos e outros sentidos. A história e a memória do discurso penitenciário representados na exposição parecem ter só uma versão, aquela do Estado, da instituição. Trata-se, como diz Orlandi, da memória de arquivo que é aquela que não se esquece. É a memória "que se institucionaliza e é arquivada". Mesmo assim, como vimos, há sempre uma versão controversa, uma possibilidade de outros gestos de interpretação e de outros/novos sentidos. Equívocos constitutivos do funcionamento da linguagem na sociedade. Não podemos esquecer das palavras de Paul Henry (2014, p. 55) em epígrafe, a saber,

não há "fato" ou "evento" histórico que não faça sentido, que não peça interpretação, que não reclame que lhe achemos causas e consequências. É nisso que consiste para nós a história, nesse fazer sentido, mesmo que possamos divergir sobre esse sentido em cada caso.

\section{Referências Bibliográficas}

ALBERGARIA, J. Noções de Criminologia. Belo Horizonte: Mandamentos, 1999.

AUTHIER-REVUZ, J. Palavras incertas: as não-coincidências do dizer. Campinas, SP: Ed. UNICAMP, 1998.

AUTHIER-REVUZ, J. "Palavras mantidas a distância". In: Entre a transparência e a opacidade: um estudo enunciativo do sentido. Porto Alegre: EDIPUCRS, 2004. p. 217237.

GUILHAUMOU, J. MALDIDIER, D. Efeitos do arquivo. A análise do discurso no lado da história. In ORLANDI, E. P. Gestos de leitura. Da história no discurso. 4.ed. Campinas: Editora da Unicamp, 2014.

HENRY, P. A história não existe? In ORLANDI, E. P. Gestos de leitura. Da história no discurso. 4.ed. Campinas: Editora da Unicamp, 2014.

MOLINA, A. G.-P. de; GOMES, L. F.. Criminologia, 4. Ed. São Paulo: RT, 2002. 
NORA, P. Entre memória e história. A problemática dos lugares. Trad. Yara Aun Khoury, In. Projeto História : Revista do Programa de Estudos Pós-Graduados de História, [S.1.], v. 10, out. 2012. ISSN 2176-2767. Disponível em: <https://revistas.pucsp.br/index.php/revph/article/view/12101/8763>. Acesso em: 18 mar. 2018.

ORLANDI, E. P. Discursos e museus: da memória e do esquecimento. In Entremeios: revista de estudos do discurso. v. 9, jul/2014. Disponível em < http://www.entremeios.inf.br >. Acesso em 08 mai. 2017.

ORLANDI, E. P. Discurso em Análise. Sujeito, sentido, ideologia. Campinas: Pontes Editores, 2012.

ORLANDI, E. P. Discurso e leitura. 8.ed. São Paulo: Cortez, 2008.

ORLANDI, E. P. As Formas do Silêncio: No Movimento dos Sentidos. 2ed. Campinas, SP: Editora da Unicamp, 2003.

ORLANDI, E. P. Análise do discurso: princípios e procedimentos. Campinas: Pontes, 2002.

ORLANDI, E. P. Discurso e texto. Formulação e circulação dos sentidos. Campinas, SP: Pontes Editores, 2001

PÊCHEUX, M. Ler o arquivo hoje. In ORLANDI, E. P. Gestos de leitura. Da história no discurso. 4.ed. Campinas: Editora da Unicamp, 2014.

PÊCHEUX, M. (1969). “Análise Automática do Discurso (AAD-69)”. In: GADET, F. \& HAK, T. (Orgs.). Por uma Análise Automática do Discurso: uma introdução à obra de Michel Pêcheux. 3.ed. Trad. Coletiva. Campinas, SP: Editora da Unicamp, 1997. p. 61-16.

SOBRINHO, J. S. da S.. "A língua que nos une": língua, sujeito e Estado no Museu da língua Portuguesa. 2011. 133 f. Tese (Doutorado em Linguística) - Universidade Estadual de Campinas, Campinas, 2011.

VENTURINI, M. C. Imaginário urbano: espaço de rememoração/comemoração. Passo Fundo: Editora da Universidade de Passo Fundo, 2009.

VENTURINI, M. C. (org.) Museus, arquivos e produção do conhecimento em (dis)curso. Campinas: Pontes Editores, 2017.

Data de Recebimento: 15/02/2018

Data de Aprovação: 07/06/2018 


\section{Para citar essa obra:}

MASSMMAN, Débora. Versões controversas na leitura de arquivos: o Museu Penitenciário Paulista In: RUA [online]. Volume 24, número 2 - 525-541 - e-ISSN 2179-9911 novembro/2018. Consultada no Portal Labeurb - Revista do Laboratório de Estudos Urbanos do Núcleo de Desenvolvimento da Criatividade.

http://www.labeurb.unicamp.br/rua/

Capa: Detalhe da capa do livro Cineastas Indígenas para Jovens e Crianças - guia didático para estudantes do ensino.

\section{Laboratório de Estudos Urbanos - LABEURB}

Núcleo de Desenvolvimento da Criatividade - NUDECRI

Universidade Estadual de Campinas - UNICAMP

http://www.labeurb.unicamp.br/

\section{Endereço:}

LABEURB - LABORATÓRIO DE ESTUDOS URBANOS UNICAMP/COCEN / NUDECRI

CAIXA POSTAL 6166

Campinas/SP - Brasil

CEP 13083-892

Fone/ Fax: (19) 3521-7900

Contato: http://www.labeurb.unicamp.br/contato 